\title{
ZONAS ECONÔMICAS AGROINDUSTRIAIS \\ COMBINANDO O DESENVOLVIMENTO ECONÔMICO \\ E A REFORMA AGRÁRIA NA COLÔMBIA
}

Jorge L. Esquirol

\section{INTRODUÇÃO}

O Poder Público no Brasil possui diversos instrumentos legais à sua disposição para incentivar o desenvolvimento econômico figurando, dentre eles, a transferência de imóveis públicos para entidades privadas. Os bens dominicais e terras devolutas são bens que, por serem desafetados da atividade pública, podem ser disponibilizados para este propósito. Os entes públicos se utilizam principalmente das alienaçôes de título e das concessões de direito real de uso, sejam remuneradas ou gratuitas. Entretanto, não pode a União - pela lei federal de licitações - e nem alguns estados e municípios - por suas leis específicas - realizar a doação de terras públicas a entes de direito privado.

Em todo caso, os instrumentos jurídicos disponíveis contêm diversos requisitos a serem cumpridos a fim de tutelar o interesse público. Entre eles, a transferência deve observar certas justificativas indispensáveis: exposição do interesse público, avaliação do bem, aprovação do ente legislativo e licitação pública. Ademais, o beneficiário pode ser compelido a cumprir certos requisitos, como a função que deverá ser destinada ao imóvel, o número de empregos que deverá gerar naquela localidade, o valor do investimento mínimo, e sujeição à possibilidade de reversão ou término da concessão. Não obstante, esses institutos jurídicos são bastante flexíveis. As transferências podem ser isentas dos requisitos de licitação pública. As exigências não são uniformes e nem sempre são rigorosas. As obrigações dos beneficiários podem variar muito de um caso ao outro. 
O Poder Público dispõe também de instrumentos jurídicos que lhe possibilitam realizar política social utilizando-se dos bens do Estado. Em particular, uma nova lei federal de regularização fundiária de 2017 prevê os meios disponíveis para que sejam realizadas as transferências de imóveis para fins de habitação social. Esta legislação dispõe que terrenos públicos, assim como os privados, podem ser objeto de intervenção pelo Estado. Em casos de assentamentos populacionais, devidamente reconhecidos, os assentados podem adquirir a propriedade de terras públicas ou privadas, observadas as condições estabelecidas na lei. O objetivo, nestes casos, é claramente diverso: utilizar as terras disponíveis, sejam do Estado ou de particulares, para satisfazer as necessidades básicas do indivíduo. Os instrumentos jurídicos utilizados para a formalização são o título de domínio e, de novo, a concessão de direito real de uso. Ambas as formas são inegociáveis por um período de dez anos, além de sofrerem outras limitaçôes.

Em princípio, os dois objetivos - o econômico e o social - poderiam coexistir. O Estado não está errado em buscar o avanço em ambos os fins. Entretanto, a dificuldade está na implementação, que depende dos institutos jurídicos colocados à disposição. As doaçôes e concessões podem ser facilmente manipuladas se não trouxerem, de forma clara, os encargos a serem cumpridos e o modo efetivo de controle. Uma justificativa dos benefícios ao interesse público depende dos fatores considerados. Ademais, a lei de regularização fundiária padece ainda de outra possível frustração. Os terrenos para redistribuição podem ser desviados para indivíduos e empresas não abrangidos pela legislação.

O direito formal, afinal de contas, não é capaz de conter todas as possíveis astúcias, malandragens e fraudes. Mas, talvez, possa reduzir alguns destes fenômenos por meio de combinações de instrumentos jurídicos que sejam mais difíceis de manipular. A análise comparada do direito poderia ajudar a pensar nessa direção. Especialmente neste momento quando se debate uma nova lei de licitações no Congresso Brasileiro. As fórmulas que outros países têm buscado poderiam servir pelo menos para ampliar a discussão. Outros mecanismos, além da doação pura, a concessão real de uso, e a propriedade plena podem ser considerados.

A Colômbia oferece um exemplo nesse sentido. Esse país evidencia o mesmo conflito entre políticas de desenvolvimento econômico e políticas sociais. De fato, o conflito das guerrilhas durante os últimos 50 anos nesse país ocorreu precisamente em torno da luta sobre a terra. A reivindicação de reforma agrária foi o primeiro ponto da negociação com a guerrilha em 2016 em Havana. Por outro lado, 
a Colômbia é um país em desenvolvimento. Um fator importante nas suas políticas econômicas envolve o acesso às terras produtivas para a agroindústria e a mineração. Uma recente legislação, a Lei 1.776 de 2016, tenta conciliar os dois objetivos, desenvolvimento econômico e repartição sustentável de terrenos aos camponeses sem terra.

No espírito comparado, o presente artigo tem como objetivo discutir essa nova legislação colombiana. A seção a seguir apresenta a lei com sua combinação particular de política econômica e política social em um mesmo regime. Ela condiciona a entrega de terras públicas para empresas privadas à celebração de contratos de associação com pequenos fazendeiros. A terceira seção deste artigo descreve a situação histórica na Colômbia em torno da questão da terra. As terras públicas são entendidas nesse país como patrimônio dos camponeses e elas têm sido reservadas para a redistribuição em seu benefício. A quarta seção analisa os pormenores da lei, estudando em detalhe os métodos estabelecidos para as transferências de terras. Os mecanismos nela introduzidos servem para nutrir a discussão comparada. Eles vão além da simples propriedade clássica do código civil, ou das doações e concessôes sem maiores encargos ou condições. A seção final oferece algumas conclusões.

\section{O CASO COLOMBIANO}

A Colômbia promulgou nova legislação em 2016 a fim de promover o desenvolvimento rural em territórios remotos. Áreas específicas do território nacional serão designadas como "zonas de interesse de desenvolvimento rural, econômico e social”, conhecidas pelo acrônimo espanhol ZIDRES. Elas têm a intenção de incentivar associações entre empresários, de um lado, e pequenos e médios fazendeiros, do outro. Estes últimos precisam fazer parte dos acordos para que as associações possam se aproveitar dos benefícios trazidos pela nova lei. Dentre esses benefícios incluem-se concessões e arrendamentos de terras públicas, créditos e garantias do Estado, benefícios fiscais, capacitação técnica e garantias de estabilidade legal. Essas associações rurais irão operar como um tipo de zona de livre comércio, mas com o propósito voltado para a produção agrícola, mineração, e outras atividades econômicas.

À primeira vista, o mecanismo parece ser bastante engenhoso. Ele fornece habilidade técnica e os recursos necessários aos fazendeiros locais. Dessa forma, os esforços individuais são mais bem aproveitados e, consequentemente, eles podem alcançar uma maior produtividade. A lei identifica alguns beneficiários especiais, 
como "camponeses, trabalhadores agrários, mulheres rurais, jovem rural, e ocupantes tradicionais das terras públicas”. O termo camponês (campesino) geralmente se refere ao trabalhador agrícola que vive em áreas rurais. Em alguns contextos, o termo também se refere àqueles que reivindicam direitos à terra em que trabalham individual ou coletivamente. $\mathrm{O}$ termo pode ter ainda uma conotação mais densa. Ele pode referir-se a uma cultura própria, capaz de fundamentar uma reivindicação política por demarcação de território especial. Nesse trabalho acadêmico, o uso do termo camponês visa simplesmente abranger o conjunto dos beneficiários acima mencionados na lei. Ela identifica algumas regras especiais aos camponeses que se diferem das cláusulas aplicáveis em geral aos pequenos e médios produtores.

Adicionalmente a essa nova lei, a Colômbia está no meio de uma importante realocação territorial. Dois outros importantes programas estão, atualmente, em andamento. $\mathrm{O}$ primeiro relaciona-se com a restituição de terras àqueles que foram deslocados internamente durante o conflito armado que assolou o país por meio século. Perante a Ley de Victimas y Restitución de Tierras, Lei 1.448 de 2011, o programa, potencialmente, afetaria mais de 5 milhões de hectares de terra, caso todos os deslocados internos reclamassem suas posses anteriores. O segundo programa trata das já existentes leis de reforma agrária que determinam a distribuição de terra aos fazendeiros sem-terra e àqueles que possuem lotes menores do que o necessário à sobrevivência. A reforma agrária recebeu recentemente um importante apoio devido ao acordo de paz celebrado em 2016 com o principal movimento guerrilheiro do país: Fuerzas Armadas Revolucionarias de Colômbia (FARC). O referido acordo prevê que o governo redistribua três milhões de hectares durante os próximos 12 anos.

A maioria dos beneficiários dos programas de restituição e de redistribuição será composta por pequenos proprietários de terra. O problema, entretanto, é que os pequenos lotes rurais não são imediatamente autossustentáveis - faltam recursos, terra adequada, água e capital. (Alvarez, 2013, p. 38-39). Dessa forma, eles demandariam significante apoio e subsídio do governo para se tornar comercialmente viáveis. A associação entre o agronegócio, como contemplada pela lei das ZIDRES, pode se tornar um importante impulso. Ela poderia fazer com que pequenos proprietários de terra se tornassem mais produtivos e autossustentáveis.

Para os empresários agricultores, o desenvolvimento dessas zonas rurais oferece a grande vantagem de fornecer terras públicas para uso agroindustrial. A lei nacional de reforma agrária pró́be a transferência integral de terras públicas para 
entidades empresárias, a menos que autorizado excepcionalmente em zonas empresárias especiais. Porém, essas zonas de desenvolvimento empresarial (ZDE), contempladas na mesma lei de reforma agrária de 1994, nunca foram regulamentadas de maneira suficiente para a sua implementação. Dessa forma, como essas exceções nunca existiram, as terras públicas desocupadas são comumente entendidas como reservadas para os beneficiários principais da lei da reforma agrária, quer dizer os "campesinos" e outros beneficiários de baixa renda.

A nova lei das ZIDRES prevê, de fato, um conteúdo às zonas empresáriais contempladas excepcionalmente na lei da reforma agrária de 1994, mas nunca antes efetuadas. Uma associação unindo os interesses dos empresários com os dos camponeses é, ademais, uma alternativa que aparenta conciliar os objetivos de redistribuição com o uso empresarial. E isso acontece sem que haja a necessidade de alterar a estrutura da lei de reforma agrária anterior. Essa fórmula de associação, ainda, evitaria problemas de inconstitucionalidade baseados em argumentos que sustentam que a medida faria regredir direitos econômicos e sociais já adquiridos pelos beneficiários principais da reforma agrária. Ao contrário, a nova lei parece só regulamentar, mesmo que de forma mais estreita, as zonas empresárias previamente anunciadas, combinando-as com objetivos de redistribuição. As concessões de terras públicas a empresas dependerão, nas ZIDRES, da existência de associações entre empresários e pequenos fazendeiros. Mas, o resultado final é que terras públicas poderão, doravante, ser destinadas legalmente ao desenvolvimento agrícola no modelo agroindustrial.

Existem muitos críticos a esse projeto. Há os óbvios problemas de desigualdade de poder de barganha. Camponeses e pequenos fazendeiros estão em grande desvantagem ao negociar os termos dos acordos associativos. Sem uma assessoria significativa, eles poderiam chegar a ter como benefício efetivo apenas um mero salário em troca do seu trabalho. A legislação não exige uma formalização dos direitos de propriedade pertencentes a cada sócio antes da aprovação do acordo. Camponeses podem, assim, ter ainda menos vantagens se só tiverem a possibilidade de pleitear a ocupação da terra. Eles estariam sujeitos aos critérios da associação para garantir o uso da terra e eventual reconhecimento de direitos reais individuais.

Esse artigo considera as novas zonas de desenvolvimento rural da Colômbia principalmente pela perspectiva da redistribuição. Requerer acordos com pequenos fazendeiros pode trazer algumas vantagens. Entretanto, sem uma supervisão significativa, esses acordos serão meramente de fachada. Eles poderiam servir simples- 
mente para contornar os objetivos das leis existentes de reforma agrária do país. Não obstante, a nova lei oferece pontos de discussão na técnica de direito privado para promover diversos fins de políticas públicas.

\section{HISTÓRICO DA POLÍTICA RURAL COLOMBIANA}

A concentração de terras é um problema constante na história da Colômbia. Números exatos são difíceis de obter em razão dos registros cadastrais incompletos e da grande quantidade de proprietários informais. Entretanto, a Colômbia é frequentemente colocada entre os países que possuem as distribuições de terra mais desiguais do mundo (Informe Nacional de Desarrollo Humano, 2011, p. 197). O governo tem buscado, desde 1936, melhorar essa situação por meio de programas de reforma agrária. As transferências de terra realizadas de grandes para pequenos proprietários aconteceram, mas não foram suficientes para promover uma transformação profunda.

A lei de reforma agrária de 1936 foi a primeira a introduzir a extinção de domínio, sem ressarcimento, contra grandes proprietários que não utilizavam suas terras de forma produtiva. ${ }^{153}$ (Colômbia, Lei 200, 1936). Nesse período, também foram assegurados direitos à terra aos posseiros irregulares em terras privadas, salvo na hipótese do antigo proprietário demonstrar o título original (a prova diabólica) fornecido pelo Estado ou vinte anos de transcriçõos registradas. Ainda, o período de usucapião em terras privadas foi reduzido. E, ademais, ações expropriatórias, desta vez com ressarcimento, foram mais adiante autorizadas para os propósitos de reforma agrária (Colômbia, Lei 160, 1994, art. 33).

Com a lei de reforma agrária de 1994, o Estado passou a dispor de uma ferramenta adicional: a compra de terras privadas para redistribuição. De fato, tal postura deve ser testada antes de empregar outros meios, como a extinção de domínio ou a desapropriação (Colômbia, Lei 160, 1994, art. 31). As novas propriedades adquiridas pelo Estado entram no inventário de "baldios" ou terras desocupadas

153 Desde a emenda constitucional de 1936, a propriedade privada na Colômbia precisa cumprir a função social. Para terras rurais, essa função refere-se é a exploração produtiva. Se o proprietário deixa de explorar produtivamente a terra por dez anos ou mais, o poder público pode iniciar procedimento administrativo para extinguir o título de propriedade. A lei de reforma agrária e a regulamentação em implementação especifica os requerimentos mínimos para a exploração. Entre os anos de 1961 a 1994, essas ações foram realizadas com frequência. Após, elas foram sofreram grande redução. 
do Estado. A agência de reforma agrária é, então, incumbida de outorgar lotes individuais aos beneficiários elegíveis. A lei de 1994 também introduziu a possibilidade de compra e venda diretamente por parte dos beneficiários da reforma agrária. Com o acompanhamento da agência responsável, o INCODER, um subsídio do Estado é providenciado para efetuar a compra no livre mercado. O subsídio original era de $70 \%$ do valor da terra. Desde 2003, o Estado contribui diretamente com $50 \%$ e o restante pode ser feito por meio de empréstimos com juros subsidiados. Portanto, o principal veículo de redistribuição de terras nos últimos tempos tem sido os subsídios fornecidos pelo Estado (Colômbia, Lei 160, 1994, art. 33).

A reforma agrária foi recentemente fortalecida no acordo de paz com o grupo guerrilheiro das FARC, tendo sido o primeiro tópico de negociação. Ratificado em dezembro de 2016, o acordo contém diversos dispositivos que reforçam o antigo compromisso do governo acerca da redistribuição de terras. Como já mencionado, espera-se que três milhões de hectares de terras sejam distribuídos dentro dos próximos doze anos. Um banco de terras para redistribuição será disponibilizado por vários meios, alguns deles já empregados no passado: extinção de título; expropriação; doação de terceiros, e terras públicas desocupadas, que são as principais fontes. Zonas de Reserva Camponesa (ZRC), que são muito diferentes da zona de reserva empresarial (ZRE) ou das mesmas zonas agroindustriais (ZIDRES), também estão contempladas. A reserva camponesa é uma designação de área reservada para a agricultura camponesa, aprovada na lei da reforma agrária de 1994 e mencionada no acordo de paz como parte da reforma agrária. Porém, o acordo não possui nenhuma disposição adicional capaz de fortalecer essa figura jurídica já existente, mas pouco utilizada.

Todavia, a principal fonte para a redistribuição será as terras públicas desocupadas (baldíos). Essas áreas podem estar, em alguns casos, completamente inabitadas. Mas, normalmente, elas estão já se encontram ocupadas, nelas trabalham fazendeiros, camponeses, ou empresas privadas. Embora possam ser entendidas como propriedade privada pelos seus posseiros, não há título válido que o comprove. Em alguns casos, as parcelas de terras em questão podem nunca ter saído do domínio público, embora também possam ser terras que pertenciam ao domínio privado, mas foram revertidas ao poder público. Isso pode ter acontecido por meio de processos de extinção de domínio ou de ações expropriatórias, como mencionado acima. Ainda, elas podem ser terras confiscadas pelo Estado em açôes civis. A Colômbia é um dos primeiros países da América Latina com extinção de título sobre bens relacionados ao cometimento de algum delito. 
Outro processo de redistribuição de terras ou, mais propriamente dito, de restituição está atualmente em andamento. A Lei das Vítimas e Restituição de Terras, de 2011, estabeleceu novos "tribunais de terras" - juizados com amplos poderes - para ouvir as reclamações de deslocados internos remanescentes da guerra que pedem a restituição de suas terras. Antigos proprietários formais, posseiros irregulares em terras privadas e ocupantes informais em terras públicas são todos elegíveis. Apesar de enfrentar resistência política de várias partes e nem todos os deslocados internos terem interesse em retornar, mais de 6.000 casos de restituição já foram decididos até julho de 2017, conforme informação do jornal "El Tiempo" (El Tiempo. Procesos). E os juízes de terras já cancelaram o título de propriedade de várias empresas agrícolas e mineradoras assentadas em áreas de desalojamento. ${ }^{154}$

Dessa forma, tanto a redistribuição quanto a restituição são institutos que pressionam as terras disponíveis. A questão não se reporta apenas aos limites físicos da terra produtiva, mas também aos diversos objetivos em conflito. De fato, a controvérsia contemporânea sobre a política rural colombiana é comumente descrita como um choque de dois modelos. Um modelo é o desenvolvimento econômico que depende da agricultura industrial. Ele visa fazer a produção mais eficiente e internacionalmente competitiva, mas depende da concentração da terra nas mãos de empresas privadas. $\mathrm{O}$ outro modelo é de associação de pequenos fazendeiros. Esse modelo é exemplificado pelos programas de redistribuição e restituição. Ele visa distribuir as atuais terras concentradas entre a população rural do país e, possivelmente, atrair de volta aqueles que já haviam deixado suas terras. Esse modelo se esbarra em dificuldades de produtividade e competitividade. Além disso, ao menos por ora, requer o apoio do Estado para tornar-se mais competitivo, mesmo que estudos comparados demonstrem que as pequenas fazendas podem chegar a ser igualmente ou mais produtivas (ALVAREZ, 2013, p. 38-39). O modelo associativo cumpre ainda outro propósito: o de programa de política social nas áreas rurais capaz de prover um tipo de proteção ao bem-estar social no campo.

\footnotetext{
154 Procedimentos de restituição exigem do requerente um conjunto probatório mínimo inicial que demonstre sua anterior conexão com a terra; presunçôes legais a seu favor que invalidem transferências anteriores; e a mudança do ônus da prova para que o oponente demonstre um alto nível de boa-fé. Prevalecendo sob o oponente não lhe dá o direito de permanecer na terra, mas sim de receber compensação do Estado. Requerimentos de restituição podem ser trazidos por pessoas que perderam sua posse desde 1991 até a expiração da lei em 2021, renovável por um prazo maior pela legislação.
} 
Em todo caso, devido às particularidades da lei e da história da Colômbia, as concessóes e arrendamentos ocorridos perante a nova lei das ZIDRES se baseiam na participação dos pequenos fazendeiros. E, dado que eles podem participar sem que sejam proprietários formais, a lei das ZIDRES serve como um meio indireto de reconhecimento de posse informal da terra pública. É claro que novas leis poderiam simplesmente expandir o universo de beneficiários elegíveis a terras públicas vagas. O poder legislativo pode emendar as leis de reforma agrária por completo. E, isso poderia permitir doações ou vendas de terras públicas para fins de desenvolvimento agroindustrial, mineração e outras atividades em qualquer lugar.

Porém, há que se considerar a existência de restrições constitucionais. Uma delas é o princípio da proibição do retrocesso, que abrange direitos econômicos e sociais.. No que tange a tal lei, a Corte Constitucional Colombiana já examinou estes argumentos e não encontrou qualquer violação constitucional. Porém, uma legislação diferente que elimine os direitos adquiridos e as expectativas inseridas na lei de reforma agrária de 1994 poderia acarretar problemas constitucionais. Em todo caso, mudanças no regime de terras públicas são capazes de provocar uma forte reação política, pois há que se levar em consideração a longa história de guerras internas na Colômbia em razão dessas questões e o compromisso feito pelo governo no recente acordo de paz com as FARC. Portanto, é mais expediente, de fato, agir de uma forma indireta - como a nova lei estabelece nas associaçôes - para tornar as terras públicas disponíveis para exploração agroindustrial em grande escala.

\section{ZIDRES: UMA ALTERNATIVA AO CHOQUE DE MODELOS?}

A legislação das ZIDRES parece ser uma tentativa de ir além do impasse entre os dois modelos. Ela incentiva associações entre os promotores agroindustriais e os pequenos e médios produtores, camponeses sem terras, e trabalhadores agrários. Os principais benefícios na lei estão condicionados a essas associações (Colômbia, Lei 1.776, 2016, artigos $7^{\circ}$ e 13). O investidor associado com camponês tem acesso a todos os incentivos fiscais oferecidos pela legislação e o investidor associado com pequeno ou médio produtor - não necessariamente camponês - tem acesso a muitos dos mesmos benefícios, incluindo concessões de direitos reais de terras do Estado mas não a transferência de domínio destas.

As empresas privadas também podem investir de forma autônoma nas ZIDRES. A lei autoriza projetos produtivos que não formam associações. Mas, nesse caso, elas podem apenas operar em propriedade privada, não obtendo acesso a 


\section{•• Série Direito, Economia e Sociedade}

terras públicas. Cumpre ressaltar que esses projetos não são elegíveis aos outros benefícios especiais concedidos pela lei.

As ZIDRES são limitadas fisicamente a áreas designadas pelo governo. Elas foram criadas para desenvolver áreas isoladas e de difícil acesso aos centros urbanos - onde os custos de produção são altos; não existe infraestrutura mínima; existem altos índices de pobreza ou a área é pouco populosa (Colômbia, Lei 1.776, 2016, artigo $1^{\circ}$ ). Em princípio, deverão ser áreas menos desejadas, ou até mesmo não aptas para concessões de terra dentro do programa da reforma agrária. Por outro lado, a legislação de reforma agrária requer um mínimo de condições que possibilitem o desenvolvimento da atividade agropecuária prévia a distribuição de terras aos pequenos fazendeiros favorecidos no programa. As áreas objeto das ZIDRES seriam distantes e muito custosas para explorar sem um investimento significativo de recursos e, a princípio, não se qualificariam para distribuição na reforma agrária. Uma zona deste tipo em um território concreto só pode ser declarada depois da sua proposição pelo Ministério de Agricultura, por meio de um decreto do Conselho de Ministros (Colômbia, Lei 1.776, 2016, artigo 21).

O que é oferecido ao investidor privado é um regime legal especial negociado para cada projeto apresentado em associação com pequenos fazendeiros ou camponeses. Os benefícios dependem das caraterísticas particulares e dos arranjos propostos. O Estado oferece, por sua vez, uma quantidade de incentivos fiscais, créditos e garantias, treinamento e assistência técnica. Além disso, são oferecidas terras de domínio público, as chamadas terras baldías que, na legislação agrária, são principalmente dedicadas aos camponeses. Ademais, os investimentos privados realizados nas ZIDRES estão protegidos contra os riscos de uma posterior alteração legislativa (Colômbia, Lei 1.776, 2016, artigo 8º). A lei funciona como uma garantia de estabilidade legal. Assim como nos casos de proteção contratual concedida pelo governo aos investidores individuais (legal stability contracts), a legislação assegura que o investidor não incorrerá em custos adicionais em razão de alterações legislativas. Caso as leis do país mudem, o investidor estará sujeito apenas às regras vigentes no período em que os contratos relacionados às ZIDRES foram executados.

No modelo original adotado pelo legislador, o esquema de associação era também um instrumento adicional para providenciar parcelas de terras aos camponeses. Num projeto produtivo em associação com eles, os promotores deveriam estabelecer "um mecanismo que permitisse" que os camponeses pudessem comprar uma porção da área, nos casos de projetos realizados em propriedade privada. (Co- 
lômbia, Lei 1.776, 2016, artigo 17). O tamanho das parcelas de terra seria determinado pelo Ministério da Agricultura, segundo o projeto produtivo apresentado e os recursos do investidor. E, no caso de projetos elaborados sobre propriedade pública, os empresários deveriam ajudar os camponeses a obter as concessóes do Estado que lhes correspondem. Essas obrigações por parte do autor do projeto tinham que ser cumpridas dentro de um prazo de três anos contados da aprovação do projeto, sob pena de revogação da aprovação. Desse modo, a lei criava uma forma adicional para os camponeses obterem uma parcela de terra.

Porém, a Corte Constitucional colombiana, em fevereiro de 2017, declarou esse artigo da lei inconstitucional ${ }^{155}$ (Corte Constitucional da Colômbia, C-077, 2017). Segundo a Corte, o artigo era inconstitucional porque ameaça os direitos mínimos dos camponeses. O Estado não pode delegar o "mecanismo" de redistribuição aos particulares, diz a Alta Corte. O temor é que em caso de propriedade privada transferida, assim como o tamanho das parcelas de terra, os termos de compra poderiam ser inferiores aos parâmetros estabelecidos na lei de reforma agrária.

Não obstante, a lei tem sido promovida inicialmente com dupla função: uma medida de desenvolvimento econômico e uma medida de assistência público-privada aos camponeses e trabalhadores rurais. A agricultura industrial terá maior acesso à terra e camponeses irão manter ou adquirir novos terrenos enquanto os empreguem em projetos produtivos. Eles também contribuem com seu trabalho e obtêm lucros de suas porçôes do investimento. Esse arranjo pode, de fato, trazer o investimento empresarial necessário às comunidades camponesas. Isso incentiva as empresas a se juntarem aos camponeses como sócios. O Estado, dessa forma, fornece benefícios econômicos e legais.

De fato, a maior justificativa para essa lei é sua habilidade de promover um modelo de agricultura associativo: pequenos fazendeiros, incluindo camponeses, trabalhando em associação. Só que as associações também incluem empresas que podem aportar recursos. Por sua vez, as empresas precisam dos camponeses para se

155 A decisão da Corte é contraditória. De um lado, considera que a lei não é uma incursão inconstitucional nos baldios reservados aos camponeses na legislação anterior, porque as terras nas ZIDRES não são aptas para a reforma agrária (não são suficientemente accessíveis e produtivas). Mas, por outro lado, diz que essas terras não podem ser parceladas pelos entes privados aos camponeses, porque só o Estado pode fazer isso nos parâmetros requeridos pela lei. Porém, acabam dizendo que, pelo inciso anterior, essas terras não são aptas a serem distribuídas pelo Estado a camponeses. 


\section{•• Série Direito, Economia e Sociedade}

qualificar para todos os benefícios oferecidos pela lei. Note-se que, ainda assim, a condição para se obter terras públicas é a formação de uma associação com pequenos e médios fazendeiros, uma categoria diferente dos "campesinos" na legislação. ${ }^{156}$

Entretanto, não existe nenhuma garantia concreta de que os camponeses visados pela legislação se tornarão membros das associações ou que serão integralmente considerados. Eles estão numa posição de desvantagem notória no momento de negociar com sócios empresários. Críticos a esse modelo alegam que a única maneira de melhorar a posição dos camponeses seria conceder-lhes títulos à terra para depois poderem negociar com mais capacidade os termos da sua associação. Ademais, caso o terreno subjacente torne-se apto para a reforma agrária, os camponeses e pequenos fazendeiros são, em verdade, os únicos, diante da lei de reforma agrária, que devem receber o título, como será discutido mais detalhadamente abaixo.

Alguns críticos temem que toda essa legislação das ZIDRES possa servir apenas para que as empresas contornem a lei da reforma agrária. Por meio da inclusão de pequenos e médios produtores em suas associações, entidades empresárias tornam-se elegíveis a receber concessões e arrendamentos de longo prazo. Essas concessões e arrendamentos possuem uma função equivalente ao título, mas em associação com pequenos fazendeiros não enfrentariam a mesma reação política, se comparadas com transferências de domínio de terras públicas diretamente para empresas agroindustriais.

\section{a. Transferências de Terras nas ZIDRES}

As terras localizadas nas ZIDRES não precisam ser adquiridas sob nenhuma forma jurídica específica. Elas podem consistir numa combinação de diferentes tipologias: propriedade privada, posse, locação. Além disso, um terreno maior pode ser agrupado sob uma combinação de diferentes tipos. As terras subjacentes podem ser compradas ou alugadas, caso consistam em propriedade privada.

Em caso de terras públicas, a propriedade não pode ser doada ou vendida diretamente para empresas privadas ou associações. Entretanto, para projetos em associação com pequenos fazendeiros, terras públicas podem ser transmitidas por concessão,

156 A legislação e mesmo a Corte Constitucional, não enfatizam esta diferença. Na verdade, as utilizam indistintamente como se fossem sinônimos. Mas, nas partes operativas da lei, os diferentes termos produzem efeitos muito distintos. O principal deles é o acesso a terras públicas. A associação com camponeses não é necessária, só com pequenos e médios fazendeiros é suficiente, conforme estabelece o artigo 13, Lei 1.776 de 2016. 
arrendamento ou outro tipo de contrato similar. $\mathrm{O}$ prazo desses arranjos depende do tempo de vida produtiva do projeto. Eles também estão sujeitos ao pagamento de aluguel e ao confisco, caso não explorado dentro do período de três anos.

De fato, um dos aspectos mais controversos da legislação das ZIDRES é sua garantia ao acesso a terras públicas, conhecidas como baldios, dentro da legislação colombiana. Essas terras identificam-se como terras que não se inserem no domínio privado ou terras que eram de propriedade privada e reverteram ao Estado. Diante da lei anterior colombiana, apenas os beneficiários da reforma agrária poderiam requerer o título legal das terras públicas disponíveis, após um período de cinco anos nela trabalhados (Colômbia, Lei 160, 1994, artigos 69 e 72). Especificamente, o artigo 65 da Lei 160 de 1994 assim dispõe:

Não poderá ocorrer a adjudicação de terrenos vagos (baldíos) a não ser que haja ocupação prévia em terras com potencial para agropecuária e desde que estejam sendo exploradas conforme as normas de proteção e utilização racional dos recursos naturais renováveis, em favor de pessoas naturais, empresas comunitárias e cooperativas de camponeses nas extensões e condiçôes designadas pela Junta Diretiva para cada município ou região do país (Colômbia, Lei 160, 1994, artigo 65).

Existem também limites no patrimônio máximo pessoal para a elegibilidade à reforma agraria (Colômbia, Lei 160, 1994, artigo 71). Assim, nesta norma, as terras públicas disponíveis têm sido reservadas essencialmente para distribuição a camponeses. ${ }^{157}$ Isso faz parte integral da política de reforma agrária para reduzir a concentração de terras.

Ressalta-se uma significativa exceção na lei de 1994. São as "zonas de desarrollo empresarial” (ZDE) mencionadas acima (Colômbia, Lei 160, 1994, artigo 82). Trata-se de áreas especiais que podem ser demarcadas pela agência de reforma agrária, observando-se alguns requisitos. Dentro dessas áreas, terras públicas disponíveis podem ser asseguradas às empresas de agricultura e pecuária. Segundo a antiga lei, elas estão sujeitas a vários requerimentos, incluindo um contrato com a agência especificando a quantidade mínima de cultivo ou de pecuária (Colômbia, Lei 160, 1994, artigo 83). Após a conclusão bem sucedida de um contrato de cinco anos, o título de domínio seria entregue à entidade privada. A agência de reforma agrária desenvolveu algumas normas internas para a implementação da lei (INCORA, Acordo 028, 1995). Mas, aparentemente, elas nunca foram aplicadas.

157 A lei refere ao potencial requerente da petição para a garantia de terras públicas simplesmente como "la persona que solicite." 
De toda forma, essas disposições de 1994 sobre as ZDE's não eliminaram a destinação principal das terras públicas aos camponeses. As ZDE's seriam somente a exceção.

Salvo o disposto no artigo 83 (zonas de desenvolvimento empresarial) da presente lei, as zonas de colonização e aquelas onde predominam a existência de terras vagas, são zonas de reserva camponesa (Colômbia, Lei 160, 1994, artigo 81).

Fora das ZDE's, que nunca existiram, entidades empresárias não teriam direito às terras públicas. Estas últimas são reservadas aos camponeses e, ulteriormente, às Zonas de Reserva Camponesa (ZDR). A legislação das ZIDRES evidencia-se, para algumas pessoas, como o atual desenvolvimento das nunca implementadas ZDE's. É assim mesmo que a Corte Constitucional colombiana enxerga a nova tipificação, como a continuação das ZDE's previamente autorizadas. (Corte Constitucional da Colômbia, C-077, 2017). Desse modo, uma associação com camponeses, ou pequenos fazendeiros, não seria sequer estritamente necessária. As ZDE's já contemplavam baldios para uso de desenvolvimento econômico. Trata-se da leitura oficial da norma por parte da Corte, mas a lei das ZIDRES também responde a uma realidade política bem diferente. Os baldios são comumente entendidos no discurso nacional como patrimônio dos camponeses.

Os projetos econômicos contemplados nas ZIDRES não precisam, forçosamente, incluir camponeses. Mas sua participação traz maiores benefícios. Como já explicado, as associações formadas com pequenos e médios fazendeiros, se não camponeses, podem aproveitar da concessão de uso ou do aluguel de terras públicas. Em caso de terra apta para a agropecuária (que não deveria ser o caso considerando os propósitos da lei das ZIDRES), essa seria a mesma terra reservada para a reforma agrária. Apenas casos excepcionais de terra de má qualidade e inacessibilidade ficariam fora do alcance da reforma agrária e, consequentemente, seriam objeto apropriado das ZIDRES. Em todo caso, a disposição na lei sobre a entrega de terras públicas prevê que:

Para a execução dos projetos produtivos será possível solicitar ao Governo Nacional a entrega em concessão, arrendamento ou qualquer outra modalidade contratual não translativa de domínio de bens imóveis da Nação localizados nas ZIDRES, com a finalidade de executar os projetos produtivos que fazem referência ao artigo 30 dessa lei. De toda forma, a entrega de imóveis da Nação só ocorrerá quando se trate de projetos produtivos que beneficiem o pequeno e médio produtor (Colômbia, Lei $1.776,2016$, artigo 13).

Esse é o benefício mais importante da lei. Não outorga título pleno para as empresas agropecuárias, porém, oferece outros direitos reais que possuem a mesma 
função. A única condição é que envolva projetos associativos e beneficie pequenos ou médios produtores. Notavelmente, nesse artigo, a lei não se refere à condição de ter camponeses na associação. Aqui a condição explícita é uma associação com pequenos produtores. A aplicação futura demonstrará como essa cláusula será implementada na prática.

\section{b. Eliminação de limitações nas transferências secundárias de terras originariamente públicas}

A lei de reforma agrária de 1994 impõe limitações adicionais às terras previamente públicas. As alienações de terrenos públicos a beneficiários elegíveis da reforma agrária devem conformar-se à "unidade de agricultura familiar" (em espanhol, Unidad Agrícola Familiar - "UAF”) ${ }^{158}$ (Colômbia, Lei 160, 1994, artigo 69). Isso significa que essas parcelas de terra precisam ser suficientes para a agricultura de subsistência sendo capazes de sustentar uma família média. Elas variam em tamanho dependendo da região, do terreno e outros fatores levados em consideração pela agência de reforma agrária. As UAF têm uma limitação temporal de 12 anos para que possam ser alienadas. Depois desse período, elas podem ser vendidas, mas com algumas limitações: não podem ser alienadas àqueles que já possuem outra propriedade imóvel, a menos que as dimensões somadas sejam inferiores a uma unidade de agricultura familiar. Essas mesmas restrições também recaem sobre as alienaçóes sucessivas. E se aplicariam, potencialmente, a terras que fariam parte de um terreno numa ZIDRES.

De fato, os terrenos públicos originariamente concedidos como UAF’s estão sujeitos a restrições futuras no que tange a transferências secundárias. Isso acaba por torná-los virtualmente inacessíveis à agroindústria que procura grandes dimensões de terra. A lei de 1994 inclui essas restrições nas concessões estatais das UAF's e parece estendê-las retroativamente a todas as terras outorgadas pelo Estado. Essas abrangeriam também as UAF'S previamente entregues aos beneficiários da reforma agrária antes de 1994. De fato, a transferência para terceiros numa venda posterior é restrita às condições na lei, sujeita a reversão do lote para o Estado no caso contrário. Segundo a lei:

158 Ver também artigo 81 da lei "as zonas de colonização e aquelas onde predominam a existência de terrenos vagos, são zonas de reserva camponesa”. Artigo 38, Lei 160 de 1994. 
Nenhuma pessoa poderá adquirir a propriedade sobre terrenos previamente adjudicados como vagos ("badíos"), se as extensões excederem os limites máximos para a concessão de titularidade designados pela Junta Diretiva para as unidades agrícolas familiares no respectivo município ou região. Também serão nulos os atos ou contratos em virtude dos quais uma pessoa constitui uma sociedade ou comunidade de qualquer natureza, utilizando-se da propriedade de terra que lhe houver sido adjudicada como vaga se, com esta terra, ditas sociedades ou comunidades consolidam a propriedade sobre tais terrenos em superfícies que excedam o fixado pelo Instituto para a Unidade Agrícola Familiar (Colômbia, Lei 160, 1994, artigo 72).

A lei de 1994 proibiu a transferência das terras originalmente pertencentes ao Estado, que acabaria por aumentar a concentração de mais de uma UAF nas mãos de um só comprador. Isso torna as terras públicas previamente concedidas aos camponeses praticamente indisponíveis para a compra por grandes projetos que necessitam de mais do que apenas uma quantidade mínima de terra. A lei das ZIDRES remove parcialmente essa restrição dispondo que ela só é aplicável a propriedades públicas titularizadas após a lei de 1994 e não antes dela. (Colômbia, Lei $1.776,2016$, artigo $3^{\circ}, \$ 3^{\circ}$ ) A lei de 1994 tinha sido considerada retroativa. A nova lei das ZIDRES esclarece essa situação pela via legislativa.

De fato, uma possível fonte de terras para as associações localizadas nas ZIDRES seria as transferências de terras públicas previamente concedidas a entes privados, conforme se vê no comunicado à imprensa da "Sociedad de Agricultores de Colombia" (Comunicado, 29 de janeiro, 2016). Estas terras ostentam títulos de domínio normalmente conferidos aos beneficiários da reforma agrária. Essa poderia ser uma importante contribuição dos camponeses-com-terra participantes nas associações. De fato, o argumento a favor de maior poder negocial para os camponeses pede uma titulação prévia às associações. Os títulos individuais, neste caso, sequer precisariam ser transferidos. Eles poderiam conformar parte da associação numa modalidade contratual.

Não obstante, as UAF's obtidas depois de 1994 não poderão ser transferidas ou juntadas numa associação. ${ }^{159}$ Somente aquelas obtidas antes de 1994, quando as restrições não eram ainda legisladas, podem participar. Não fica claro na legislação, então, como novas concessões de UAF's previstas para os camponeses, a única modalidade de transferência na reforma agrária, podem participar nas ZIDRES. Tendo em vista as limitações na lei de reforma agrária citadas acima, mesmo as associações em modo contratual com proprietários de UAF’s seriam aparentemente proibidas.

159 Ver restriçōes no $\$ 3^{\circ}$, artigo 3 da Lei 1.776 de 2016. 
Esse pode ser um ponto de dificuldade na legislação das ZIDRES. Os camponeses com UAF's depois de 1994, ou aqueles que obtiverem UAF's no transcurso do projeto de associação, são incapazes de contribuir com sua propriedade imóvel para a associação. Seria uma contradição com os propósitos principais da legislação. Não obstante, a não transferência das UAF's em parcelas maiores é uma posição defendida de modo ferrenho pelos aliados dos camponeses. Agindo desse modo, eles esperam que a economia camponesa seja melhor salvaguardada.

\section{c. Terras públicas não formalmente atribuídas}

A legislação das ZIDRES adota uma posição receptiva à informalidade legal. Normalmente, a informalidade é vista de forma amplamente negativa para o desenvolvimento econômico. Informalidade na esfera da propriedade, em particular, é associada com improdutividade de bens, incerteza legal e posse insegura. Entretanto, as associações nas ZIDRES podem fazer uso dos direitos informais dos camponeses. Terras públicas não formalmente atribuídas dentro de uma ZIDRES podem ficar em uma situação de relativa suspensão. Durante o processo de aprovação de uma associação, elas só precisam figurar dentro de um plano de formalização (Colômbia, Lei 1.776, 2016, artigo 16). Os direitos à terra de todo o território não precisam ficar definitivamente resolvidos antes da formação das ZIDRES ou da aprovação dos projetos produtivos. Entretanto, projetos podem prosseguir na forma de um mero plano para formalizar as eventuais alienações aos camponeses. De fato, o estatuto dispóe que:

Quando o camponês, trabalhador agrário ocupante ou possuidor de boa-fé cumpre com os requisitos que o define como pequeno produtor e não possui o título que garante a propriedade da terra sobre a qual ele exerça seu trabalho agrário, o Governo Nacional garantirá a titularidade da referida terra mediante um plano de formalização da propriedade da terra dentro das ZIDRES (Colômbia, Lei 1.776, 2016, artigo 16).

Assim, a lei parece garantir que todas as reivindicações informais dos camponeses serão preservadas. Quaisquer direitos informais que um ocupante possa ter à terra pública dentro das ZIDRES não serão revogados. Pelo contrário, eles serão reconhecidos e garantidos pela legislação.

Previamente, na Lei de reforma agrária de 1994, a ocupação por parte do camponês só lhe oferecia uma "mera expectativa" de alienação de terra do Estado (Colômbia, Lei 160, 1994, artigo 65). Essa lei expressamente rejeita quaisquer "direitos constitutivos" a esses posseiros irregulares. Um direito de ocupação nas terras públicas não é formalmente reconhecido. Assim, as leis agrárias deixam claro que 


\section{•• Série Direito, Economia e Sociedade}

ocupantes de fato em terras públicas não são reconhecidos como posseiros conforme definido no Código Civil (Colômbia, Lei 160, 1994, artigo 65). Em comparação, os posseiros de propriedades privadas, no Código Civil, têm direitos reais reconhecidos e, até mesmo a adjudicação de título com o passar do tempo. Entretanto, para os ocupantes em terras públicas não existem direitos reconhecidos fora das concessões explícitas do Estado. Portanto, ocupantes informais em terras públicas não possuem "direitos adquiridos" perante a lei.

Porém, essa mera expectativa de direitos é fundamento suficiente na nova lei para o acesso às terras nas ZIDRES. A lei permite que as associações utilizem essa expectativa de direitos. Elas podem servir como parte da terra diante da qual as associaçôes das ZIDRES operam. ${ }^{160}$ De fato, a lei vai ainda mais longe. Para os ocupantes elegíveis à reforma agrária, a lei das ZIDRES reconhece a sua condição. E mais, ela garante o eventual título perante o processo de "formalização do plano". Ela prevê que, nesses casos: "o Governo Nacional garantirá a titularidade dos referidos lotes mediante um plano de formalização da propriedade da terra inserida nas ZIDRES” (Colômbia, Lei 1.776, 2016, artigo 16). Dessa forma, o governo está garantindo um título justo baseado nessas expectativas. Ele não precisa outorgar imediatamente o título formal da terra. Ele apenas prevê um "plano de formalização" para essas terras no início do projeto de associação.

Essencialmente, a associação é a beneficiária de direitos incipientes ou expectativas dos camponeses a terras públicas ocupadas por eles. A associação não recebe o título da terra pública nem das terras previamente pertencentes ao Estado que são agora classificadas como UAF's e estão sujeitas a restrições. Ela pode utilizar terras, entretanto, por meio da participação dos futuros beneficiários elegíveis à reforma agrária. Assim, a associação adquire uma espécie de direito derivado dos títulos eventuais de seus membros camponeses. São esses títulos futuros, e ainda mais essas expectativas de titulação, que figuram como elo entre as associações qualificadas e as terras públicas.

Segundo reportagens, futuros investidores também não estão insistindo em direitos absolutos de propriedade (El Espectador, 2016). De fato, eles não parecem estar

${ }^{160}$ Ressalta-se que a lei também inclui o dever de conceder aos camponeses sem terras em associação a oportunidade de comprar a terra em ZIDRES aprovadas dentro do prazo de 3 anos (artigo 17). Isso, entretanto, contempla o projeto das ZIDRES construído em propriedades privadas, presumidamente trazido pela parte empresária. É este inciso, que a Corte constitucional colombiana invalidou, como explicado acima. 
preocupados com título de propriedade. Eles querem, simplesmente, o acesso seguro à terra. De certa forma, isso não surpreende. Regularmente, entidades empresárias operam em terras alheias. Especialmente, no que tange a terras públicas, a exploração de recursos opera com concessões pelo poder público e não por transferências de titularidade. Esse é o caso, por exemplo, das atividades de mineração, visto que o poder público é o titular de todos os direitos em propriedades subterrâneas.

Nas ZIDRES, a expectativa de receber o título de propriedade é suficiente para fundamentar um projeto produtivo. Os parceiros camponeses de uma associação, elegíveis aos benefícios da reforma agrária, têm essas vantagens reconhecidas indiretamente. Ainda, o "plano de formalização" do governo, inserido na lei das ZIDRES, substituiria a exigência de uma formalização imediata. Considerando o apoio político que a lei das ZIDRES recebeu das empresas, é claro que a informalidade não é sempre preocupante ou negativa ao investimento. Além da titulação formal, outros mecanismos podem prover a certeza legal esperada.

De fato, um acordo especial do regime regulatório e fiscal mais benéfico é aparentemente suficiente para compensar a falta de títulos e formalidade. A transferência direta da propriedade de terrenos para empresas não é prevista. Entretanto, o valor dos benefícios oferecidos pelo Estado poderia ser ainda maior por meio de um regime legal especial com um nível de benefícios negociados e concessóes em terras públicas. Um regime legal especial é um significante desvio do modelo de regras aplicáveis igualmente a todos. O Estado fará, então, específicas alocações de verbas públicas e regulamentações especiais em associações aprovadas. Essas proteções adicionais para investidores significam uma importante vantagem. A eles é também garantida a estabilização legal e, portanto, um cálculo mais previsível de custos e lucros.

\section{d. Direitos de superfície}

Além das formas já mencionadas, existe ainda outro modo de adquirir o acesso à terra na lei que tem o poder de beneficiar as pessoas assentadas em zonas de ZIDRES que não são elegíveis à reforma agrária, e que não teriam sequer uma expectativa razoável de titulação na reforma agrária. Pela nova lei, aqueles que ocupam terras públicas nas ZIDRES no momento da sua formação possuem duas alternativas, previstas pelo $₫ 1^{\circ}$ do artigo 13

As pessoas que se encontram ocupando terrenos vagos (baldios) que, na data da criação das ZIDRES, não cumpram com os requisitos estabelecidos na Lei 160 de 1994 
(reforma agraria), para se beneficiarem da titulação dos terrenos ocupados, poderão se vincular aos projetos produtivos que tenham caráter associativo ou celebrar contratos de direito real de superfície, que permitam o uso, gozo e disposição da superfície dos terrenos rurais que ocupam, sem prejuízo dos direitos adquiridos. Os contratos de direito real de superfície não poderão ser celebrados nas terras abandonadas, nas terras restituídas e nos territórios étnicos.

Essas disposições, em teoria, podem ser aplicadas (1) aos ocupantes camponeses que nesse momento não são elegíveis à reforma agrária por alguma razão ou (2) ocupantes que nunca seriam elegíveis como as empresas privadas. Essa cláusula é de particular relevância àqueles que não são elegíveis de forma alguma à reforma agrária.

Segundo este parágrafo em especial, as pessoas já assentadas poderiam ingressar em uma associação. Como já sabemos, as associações são elegíveis a concessões e arrendamentos de terras públicas. O parágrafo citado deixa claro um ponto adicional: que as pessoas que já se encontram no território no momento da declaração das ZIDRES, e sem possibilidade de um título da reforma agrária, também podem fazer parte de uma associação e obter os benefícios da lei. Não obstante, a primeira parte do parágrafo confunde um pouco o entendimento, pois parece falar de um simples procedimento "para se beneficiarem da titulação". Entretanto, o benefício não é a simples titulação de direitos pré-existentes, mas criados por esta nova lei.

Alternativamente, os ocupantes atuais, inclusive as empresas, também podem ingressar em um contrato de direito à superfície. Presumivelmente, essa segunda alternativa não está condicionada à formação de uma associação. ${ }^{161}$ Assim, se essas disposiçōes forem de fato interpretadas dessa forma, entidades empresariais ocupando informalmente terras públicas e não associadas a pequenos fazendeiros podem obter direito à superfície sobre essas terras, ou até mesmo o próprio título.

Se esse é mesmo o caso, então os ocupantes inelegiveis à reforma agrária na data efetiva das ZIDRES seriam desproporcionalmente beneficiados. Esses direitos seriam muito mais benéficos a uma entidade privada do que a um camponês. $\mathrm{O}$

161 A cláusula geral do artigo 13 poderia também ser aplicada nesse caso, e uma associação ser requerida. Entretanto, se esse fosse o caso, então a sub-cláusula do Parágrafo 1 seria supérflua ou estaria no lugar errado. A determinação geral do artigo 13 já permite não apenas concessões e locaçōes, mas também "qualquer outra forma contratual que não constitua transferência de domínio". É estranha a especificação de um novo modelo como o contrato para direitos de superfície em um parágrafo separado, aplicando apenas aos ocupantes no momento da declaração das ZIDRES. 
último eventualmente teria direito a um título segundo a legislação agrária existente. Ambos caberiam na disposição legal acima, mas, é claro, seriam as empresas privadas as principais beneficiadas.

$\mathrm{Na}$ realidade, a lei é ainda nova e necessita aprimoramento. Entretanto, as ambiguidades trazem certa preocupação. Existem lacunas interpretativas que permitem que empresas atualmente situadas em terras públicas possam ser excetuadas das proibições a estas terras. Numa ZIDRES, elas poderiam ter a sua situação irregular legalizada.

\section{e. Associações com pequenos fazendeiros}

Cumpre ressaltar que as ZIDRES oferecem a possibilidade de um parceiro empresário aos camponeses e pequenos fazendeiros. Trata-se de uma alternativa à associação composta exclusivamente por camponeses nas suas respectivas comunidades. De fato, as ZIDRES não são muito diferentes de experiências legislativas anteriores na Colômbia com zonas de regulamentação especial. A lei de reforma agrária de 1994 foi a primeira a introduzir o mecanismo legal para a associação de camponeses, a "Zona de Reserva Campesina” (ZRC), e também as "Zonas de Desarrollo Empresarial" (ZDE), acima discutidas. A ZRC já é, há muito, aceita dentro da lei colombiana. Assim como as ZIDRES, ela é baseada na criação de um plano de desenvolvimento de associaçôes. No caso da Zona de Reserva Campesina, ela deve ser apresentada por uma comunidade de camponeses em uma área específica. Deve também incluir planos detalhados para produção, marketing, transporte e venda dos produtos. O governo negocia os termos e aprova regulamentos especiais e o tratamento tributário a ser implementado.

Essas zonas especiais de camponeses são descritas como uma forma de implementar o modelo de associação de fazendeiros, defendido por aqueles que são favoráveis a redistribuição de terras. Trata-se de uma resposta aos críticos que afirmam que o modelo associativo de agricultura é atualmente inviável. Ao agrupar um número de fazendeiros, eles tendem a produzir resultados que esforços individuais são incapazes de obter. O histórico dessas ZRC’s é bem marcado. Pelas contagens recentes, menos de seis dessas zonas estão atualmente em funcionamento, com ainda sete ainda em processo de aprovação (El Heraldo, 2016). Algumas outras foram aprovadas pelo governo, mas já não funcionam mais. De toda forma, isso não fez com que o governo anterior do Presidente Álvaro Uribe fizesse algo para incentivá-las. Pelo contrário, elas tiveram uma reputação negativa. Elas foram vis- 
tas por alguns como redutos de apoio às guerrilhas e laboratório de "repúblicas independentes" esquerdistas. Um aspecto importante das zonas especiais, não obstante, é que elas aproveitam de seus próprios regimes especiais de regulamentação.

Apesar do histórico controverso dessas zonas especiais camponesas, o acordo de paz com as FARC realizado no ano passado se refere a elas. De fato, as previsões acerca de reforma agrária no acordo dependem de dois procedimentos legais para se sustentarem. O primeiro é que a redistribuição de terras seja entregue aos beneficiários em forma de plena propriedade titularizada. Essa é uma faca de dois gumes, pois pode oferecer garantias de propriedade mais fortes aos titulares, porém, é mais vulnerável às pressões do mercado e aos interesses de grandes empresas em adquiri-las. Com esses perigos em mente, essas propriedades redistribuídas estarão sujeitas a uma restrição de alienação por sete anos. A proposta inicial das FARC era uma restrição de alienação de dez anos. Em todo caso, é menos do que os 12 anos atualmente requeridos pela lei colombiana da reforma agrária. Claramente, eles têm ciência de que o título de propriedade torna mais fácil o comércio dessas terras e, consequentemente, a sua reconcentração. Especialmente para setores socioeconômicos vulneráveis da sociedade, essa possibilidade é bastante previsível.

O outro importante mecanismo contido no acordo de paz é a dita zona de reserva camponesa. Nenhuma regulamentação adicional a esse mecanismo está prevista no acordo de paz. Pelo contrário, o acordo simplesmente faz referência à legislação já existente na Colômbia. Entretanto, essa seria a única outra maneira em que terras agrárias redistribuídas poderiam ser regulamentadas e colocadas em posse de fazendeiros de pequeno porte. $\mathrm{O}$ regime legal especial das ZRC's poderia proibir a alienação em áreas restritas além de impor outras regulações.

No passado, houve discussão relevante acerca da legislação da ZRC. Algumas dessas propostas têm a intenção de emendar a lei para incluir a possibilidade de parceria entre entidades não camponesas. Essas propostas geralmente encontram objeções. Elas são vistas como uma forma de desfazer as proteções almejadas das ZRC e também como uma forma de evitar as restrições existentes nas UAF's. Uma vez que parecem por demais favoráveis ao modelo de agricultura industrial de desenvolvimento rural, têm sido rejeitadas.

Atualmente, as ZIDRES contornam esses debates para emendar a legislação sobre zonas especiais sem necessidade de tocar nas ZRC's. De fato, a ZIDRES é proposta como um tipo diferente de zona especial limitada a certas e remotas terras do território nacional. Tratam-se de áreas que talvez não seriam desenvolvidas de outra forma. E, presumivelmente, as ZRC não seriam viáveis nessas localizações, 
em razão do alto nível de investimento requerido. Entretanto, tudo isso depende de cálculos sujeitos a alto grau de especulação. Notavelmente, a legislação afirma que as ZIDRES não podem ser formadas nas áreas já designadas como ZRC. Entretanto, os líderes de uma ZRC podem decidir se desejam ou não ser incluídos nos benefícios estabelecidos pela lei das ZIDRES.

\section{CONCLUSÃO}

Claramente, o caso de terras públicas desocupadas para desenvolvimento econômico é um assunto delicado na Colômbia. Não menos delicada é a questão da guerra que tem sido travada há mais de cinquenta anos, presumidamente por justiça social para os camponeses e os pobres. Nesse tema, o Superintendente de Registros e Notas tem evitado a controvérsia que suscita as ZIDRES. Ele tem afirmado, em referência à lei, que:

Títulos de propriedades não serão concedidos visto que essa lei é sobre produtividade, e não sobre títulos. A produtividade por meio do relacionamento entre camponeses e produtores sempre foi discutida e quanto a isso não há contradição (EL COLOMBIANO, 10 de fevereiro 2017).

A transferência de terras públicas a empresários e investidores é, ao mesmo tempo, um problema político e, tecnicamente, ilegal. Tomando por base a perspectiva do Superintendente, as ZIDRES não seriam, na realidade, as herdeiras das nunca implementadas ZDE's que contemplavam transferências de títulos às empresas. Isso porque o título de domínio não é transferido. Trata-se apenas de concessões e arrendamentos. Claro que as transferências de outros direitos reais podem cumprir com os mesmos objetivos. As características formais em realidade são menos importantes.

Apesar da afirmação do Superintendente, a verdade é que as ZIDRES proveem uma forma de evitar essas limitações de transferência. Quando agro-empresários se associam com camponeses e pequenos fazendeiros, o Estado pode conceder concessões e arrendamentos de terras públicas. Mas, também, o Estado não precisaria prover toda a terra. Os camponeses que já têm adquirido às terras podem colocar seus títulos de propriedade pré-1994 (previamente terra pública) conquistados pela reforma agrária a serviço dos projetos de agricultura industrial. E, mais curiosamente, para os que não têm, eles também são capazes de contribuir com seus direitos informais ou meras expectativas ao futuro título, baseado em sua contínua ocupação em terras públicas. O que não fica claro, como já explicado, são os títulos de UAF's expedidos depois de 1994, pois estes parecem não podem fazer parte. 
•• Série Direito, Economia e Sociedade

Entretanto, como mencionado acima, se o $\$ 1^{\circ}$ do artigo 13 for lido de forma literal, nem mesmo uma associação sequer seria necessária quando as ZIDRES entrarem em vigor pela primeira vez, visto que a lei autoriza um contrato de direito de superfície. As empresas ocupantes no momento da formação podem obter um contrato deste tipo do Estado.

Em todo caso, a prova estará na implementação. Nesse caso, como os críticos já ressaltaram, camponeses encontram-se em desvantagem para negociar os acordos em uma associação. Eles serão negociadores de primeira viagem, ao contrário das experientes corporaçooes. Não é necessário mencionar que eles não estarão igualmente amparados. Existe um perigo real de que a participação dos camponeses nas associações seja bastante limitada, a menos que maiores proteções sejam implementadas. Também, é difícil entender como eles irão participar, se as suas alocações de terreno não são empregáveis nas associações. Reconheço o argumento dos defensores da não acumulação das UAF's - mesmo em forma associativa. Mas, essa proibição contribui ao desempoderamento dos camponeses na participação nas ZIDRES. Eles só podem participar com UAF's alocadas pré-1994 ou com direitos informais sobre a terra. Paradoxalmente, a formalização numa UAF impede a sua participação num contrato de associação.

Talvez, afinal de contas, as ZIDRES não tenham uma aplicação direta no contexto brasileiro sem maiores ajustes. A finalidade de reconciliar objetivos de políticas de desenvolvimento e políticas sociais pode parecer muito incompleta na atual proposta colombiana. De fato, a legislação examinada mostra séria tendência a favor da agroindústria e a favor do saneamento de ocupações empresarias da terra. É claro que a legislação não contém proteções suficientes para os camponeses e avanços na reforma agrária. Contudo, convida a discussão sobre como políticas, aparentemente contraditórias, podem ser acomodadas. Pelo menos revela claramente os pontos de tensão entre os objetivos distintos num mesmo desenho legal.

\section{REFERÊNCIAS}

ALVAREZ, Jaime Forero. The economy of family farming production. Cuadernos de Desarrollo Rural, Colômbia, 10 (70), p. 27, 38-39, Special Issue.

BEJARANO A., Jesús Antonio. Economía de la Agricultura. Tercer Mundo Editores. Colombia: Bogotá, 1998.

COMUNICADO À IMPRENSA DA SOCIEDAD DE AGRICULTORES DE COLOMBIA, SAC, 29 de janeiro, 2016. Disponível em: <http://www.sac.org.co/es/sala-de- 
prensa/437-la-sociedad-de-agricultores-de-colombia-sac-celebra-la-sancion-presidencialde-la-ley-de-zidres.html>. Acesso em: 7 jul. 2017.

CORTE CONSTITUCIONAL DA COLOMBIA, C-077, 2017.

EL COLOMBIANO. Ley Zidres: con reparos aun después de aprobada. 10 de fevereiro de 2017.

EL ESPECTADOR. Empresarios defienden la ley Zidres ante la Corte Constitucional Judicial. 15 de setembro de 2016.

EL HERALDO. Dos modelos de desarrollo rural en tensión. 30 de agosto de 2016.

EL TIEMPO. Procesos de restitución de tierras llegan a áreas de conflicto. Disponível em: $<$ http://www.eltiempo.com/politica/proceso-de-paz/restitucion-de-tierras-en-zonas-deconflicto-donde-estaban-las-farc-105032>. Acesso em: 3 jul. 2017.

INSTITUTO COLOMBIANO DE REFORMA AGRARIA (INCORA), Acuerdo 028 de 1995.

LIPTON, Michael. Land Reform in Developing Countries: property rights and property wrongs. Routledge, 2009.

REPÚBLICA DE COLÔMBIA. Lei 1.448 de 2011.

REPÚBLICA DE COLÔMBIA. Lei 1.776 de 2016.

REPÚBLICA DE COLÔMBIA. Lei 160 de 1994.

REPÚBLICA DE COLÔMBIA. Lei 200 de 1936.

UNITED NATIONS DEVELOPMENT PROGRAM. Colombia rural: razones para la esperanza. Informe Nacional de Desarrollo Humano, 2011. 
